\title{
Wave length and celerity downstream from a hydraulic jump
}

\author{
Comprimento e celeridade das ondas a jusante de ressalto hidráulico
}

\author{
Ana Paula Gomes ${ }^{1}$ (D), Eduardo Pivatto Marzec ${ }^{1}$ and Luiz Augusto Magalhães Endres ${ }^{1}$ (i) \\ ${ }^{1}$ Universidade Federal do Rio Grande do Sul, Porto Alegre, RS, Brasil \\ E-mails: anapaulaa.gomes@gmail.com (APG),eduardomarzec@gmail.com@gmail.com (EPM), endres@ufrgs.br (LAME)
}

Received: February 14, 2018 - Revised: December 22, 2018 - Accepted: March 05, 2019

\begin{abstract}
The wave period, i. e., the time interval which corresponds to a complete oscillation, is an important parameter of wave characterization. It allows the estimation of other important wave characteristics such as the length and celerity. This study aims at describing the results of a relationship among the significant, mean, and peak periods of waves generated downstream from a hydraulic jump. The frequency of vortex formation in the roller region within the hydraulic jump was used. Besides those relationships, wave lengths were also determined by the dispersion equation by considering the wave-current overlapping effect in order to identify the wave celerity. Estimated results of wave celerity were compared to their experimental results. Our findings allowed us to identify that the significant wave period was the most representative period for the characterization of a wave downstream from a hydraulic jump.
\end{abstract}

Keywords: Characteristic wave period; Wave-current overlapping; Dispersion.

\section{RESUMO}

Uma característica importante para a caracterização de uma onda é o seu período, ou seja, o intervalo de tempo correspondente a uma oscilação completa. Através do período da onda é possível estimar outras importantes características da onda, tais como o comprimento e a celeridade de uma onda. Neste estudo, são apresentados resultados de uma relação entre os períodos significativo, médio e de pico, das ondas geradas a jusante de ressalto hidráulico, com a frequência de formação dos vórtices presentes na região do rolo contido dentro do ressalto hidráulico. Além destas relações, foram determinados também os comprimentos das ondas, por meio da equação de dispersão considerando o efeito de superposição de onda e corrente, para a identificação da celeridade das ondas. Os resultados estimados para a celeridade das ondas foram relacionados com os resultados experimentais obtidos para a celeridade das ondas. Através dos resultados obtidos, foi possível identificar que o período característico da onda mais representativo para a caracterização de uma onda a jusante de ressalto hidráulico foi o período significativo.

Palavras-chave: Período característico de onda; Superposição onda-corrente; Dispersão. 


\section{INTRODUCTION}

Stepped spillways consist of a form of energy dissipation structure used in dams due to the energy dissipation promoted during the flow fall, thus allowing the decrease of the energy portion that arrives at the base of the dam and, consequently, in the stilling basin.

However, the amount of energy to be dissipated by the stilling basin can erode the river banks located downstream from the dams. This is due to the action of currents and the impacts of waves generated at the end of the hydraulic jump.

The commonly used methods for the design of protection material for river banks - located downstream from hydraulic structures - use wave parameters such as wave period and height.

Although there are several works in the literature that identify wave characteristics such as period and height driven by the wind or by the action of vessels, the parameters of waves generated downstream from hydraulic structures are not commonly known.

The first known experimental work on the identification of heights and periods of waves generated downstream from a hydraulic jump was presented by Bradley and Peterka in 1957.

After the study of Bradley and Peterka (1957), only three other authors who carried out experimental studies on the identification of heights and periods of waves generated downstream from a hydraulic jump were identified: Abou-Seida in 1963, and Lopardo and Vernet in 1978.

Besides the wave height and period, two other important parameters to be identified for the characterization of a wave are its length, i. e., the distance between two crests or between two consecutive troughs, and its celerity, which is the wave propagation speed. However, no research work that addressed the study of the length and celerity of waves generated downstream from a hydraulic jump was found in the literature.

Regarding the wave length determination, Neves and Dias (2013) showed the importance of performing current profile measurements simultaneously to wave measurements in order to correctly determine kinematic parameters and wave dynamics.

According to the mentioned authors, it is fundamental to obtain detailed measurements of the velocity field - both in nature and in the laboratory -, not only for the experimental verification of rotational wave theories, but also for the correct estimation of the wave parameters.

Thus, it is of fundamental importance that measurements (either in nature or in the laboratory) that allow the identification of the flow velocity field and of the parameters of waves generated downstream from hydraulic structures are performed.

\section{LITERATURE REVIEW}

The hydraulic jump downstream from spillways or floodgates may be developed in a free or submerged (drowned) way as shown in Figure 1. The submerged hydraulic jump forms as the downstream water layer $\left(T_{n}\right)$ becomes greater than the free hydraulic jump water layer $\left(Y_{2}\right)$.

Thus, as well as the Froude number $\left(\mathrm{Fr}_{1}\right)$, another dimensionless parameter that characterizes the submerged jump is the submergence factor or coefficient $(S)$, which can be defined in different forms depending on the bibliography. The equations from the authors used as references for this research are presented below; the first one was proposed by Marques, Almeida and Endres (1999), and the following was suggested by Rajaratnam (1965):
$S=\frac{T_{W}}{Y_{2}}$

$S^{*}=\frac{T_{W}-Y_{2}}{Y_{2}}$

Two other important features of hydraulic jumps are their length and the roller length. The roller length is defined as the distance between the jump beginning section, where the fast conjugate height occurs, and the section from which the rotation movement is completed. The hydraulic jump length is defined as the distance between the sections where the conjugate heights take place. Over the years, several assumptions have been made for the determination of both the roller and the hydraulic jump lengths. Tables 1 and 2 present some suggested equations for the roller and hydraulic jump lengths, respectively.

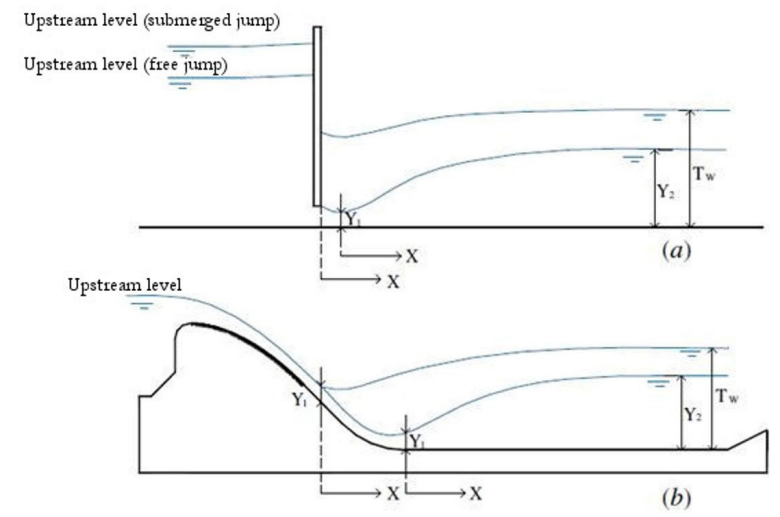

Figure 1. Hydraulic jump formed downstream from a floodgate (a) and downstream from a spillway (b). Source: Adapted from Trierweiler Neto (2006).

Table 1. Equations for the determination of the roller length as suggested by several authors.

\begin{tabular}{lcc}
\hline \multicolumn{1}{c}{ Author } & Proposed Equation & \\
\hline $\begin{array}{l}\text { Douma (1942, apud } \\
\text { Teixeira, 2003) }\end{array}$ & $L_{r}=3 Y_{2}$ & Equation 3 \\
Peterka (1974) & $L_{r}=4.5 Y_{2 .}\left(4.5 \leq F r_{I} \leq 9\right)$ & Equation 4 \\
Newmham (1973 & $L_{r}=6.3\left(F r_{l}-1\right)$ & Equation 5 \\
apud Teixeira, 2003) & $L_{r}=6\left(Y_{2}-Y_{l}\right)$ & Equation 6 \\
Marques et al. (1997) &
\end{tabular}

Where: $L_{r}$ is the roller length; $Y_{1}$ is the fast conjugate height; $Y_{2}$ is the slow conjugate height; and $\mathrm{Fr}_{1}$ is the Froude number at the beginning of the hydraulic jump. Source: Teixeira (2003).

Table 2. Equations for the determination of the free and submerged hydraulic jump length as suggested by several authors.

\begin{tabular}{lcl}
\hline \multicolumn{1}{c}{ Author } & Proposed Equation & \\
\hline Elevatorski (1959) & $L_{j}=6.9\left(Y_{2}-Y_{1}\right)$ & Equation 7 \\
$\begin{array}{l}\text { Marques, Drapeau } \\
\text { and Verrette (1997) }\end{array}$ & $L_{j}=8.5\left(Y_{2}-Y_{1}\right)$ & Equation 8 \\
$\begin{array}{l}\text { Teixeira (2003) } \\
\text { Lopardo et al. }\end{array}$ & $L_{j}=8 .\left(Y_{2}-Y_{1}\right)$ & Equation 9 \\
(2004) & $L_{j j} /\left(T_{w}-Y_{3}\right)=41\left(2 S^{*}\right)+6$, where & Equation 10 \\
\hline
\end{tabular}

Where: $L$ is the free hydraulic jump length; $L$ is the submerged hydraulic jump length; $Y_{1}$ is the fast conjugate height; $Y_{2}$ is the slow conjugate height; $T_{w}$ is the depth downstream from the submerged hydraulic jump; and $S$ is the submergence coefficient. Source: Conterato (2014). 
Hydraulic structure projects are usually carried out using the external features of the hydraulic jump such as the conjugate heights and the jump length. However, hydraulic jump internal characteristics have been becoming more relevant over the years due to the evolution of the equipment used in measurements, the need for optimization in hydraulic structure projects, and also by the evaluation of damages inflicted on the structures after decades of operation.

In this sense, Mok (2004) performed measurements of free surface variation downstream from a free hydraulic jump, establishing a relationship between the vortices formed in a region ahead of the roller and the variation of the free surface downstream from a free hydraulic jump. The author proposed an equation for the determination of the frequency of vortex formation for Froude number values greater than 1.5:

$$
\text { freq }=\frac{U_{1}}{2 L r}
$$

where: $f_{\text {req }}$ is the frequency of vortex formation in the roller region; $U_{1}$ is the velocity at the beginning of the hydraulic jump; and $L$ is the roller length.

For different Froude number values, the mentioned author obtained a good fit between the proposed expression (Equation 11) and the characteristic frequencies derived from the free surface variation at the end of the free hydraulic jump (as shown in Figure 2).

According to Lopardo and Vernet (1978), hydraulic jumps have been the object of numerous investigations on several physical aspects that are linked to them, but the knowledge on the progressive waves that this phenomenon drives in the spillway exit channels are still very scarce.

Bradley and Peterka (1957) were the pioneers in the observation of waves generated downstream from hydraulic jump energy dissipaters. In their study, these authors aimed at minimizing the effects caused by wave energy on the structure of a dam. In order to do so, four forms of structures were analyzed in a laboratory to reduce the height of the waves driven by hydraulic structures for Froude number values between 2.5 and 4.5. Among the forms of structures analyzed, the one that showed greater efficiency in the reduction of wave heights was called "underpass-type wave suppressor", where the turbulent flow was introduced into a submerged tube of variable height and length. The percentage of wave height reduction depended on the downstream water depth and on the suppressor length.

Abou-Seida (1963) sought to relate the characteristics of the waves generated downstream from a hydraulic jump - formed by means of a floodgate - with the Froude number, bed slope, and the level downstream from a free hydraulic jump. His analyzes were performed in a reduced physical model for Froude number values between 2.23 and 4.98. According to the author, the wave parameters, such as period and amplitude, showed an irregular behavior downstream from the hydraulic jump energy dissipater. The author concluded that the significant wave height $(H)$ increased as the Froude number increased for the same depth downstream from the hydraulic jump. He also observed that when the free hydraulic jump approached a stable form, i. e., Froude number values close to 4.5 , its influence on the wave height was small. With respect to the wave mean periods $\left(\mathrm{T}_{\text {mean }}\right)$, there was no relationship between them and the variation of the Froude number.
Lopardo and Vernet (1978) related the characteristics of waves generated downstream from a hydraulic jump and Froude number values that ranged from 2.16 to 6.8. They also considered the distance along the water course downstream from free and submerged hydraulic jumps, with submergences between 10 and $15 \%$. By performing experiments in a reduced physical model, the authors observed that the significant wave height $\left(H_{s}\right.$ increased as the Froude number increased. For the wave period determination, the authors considered the peak period $\left(T_{p}\right)$, i. e., the period corresponding to the frequency of higher spectral density, which showed an exponential increase as the Froude number increased.

The determination of the wave length is essential since several important parameters derive from it, such as the wave speed, wave number, dispersion ratio, horizontal and vertical wave velocities, among others.

Through Dean's stream function theory, Neves and Dias (2013) evaluated the errors in wave length values when the current was neglected, considering four types of current velocity profiles as shown in Figure 3: I) uniform, II) with constant vorticity, III) exponential, and IV) cosine.

In case ' $I$ ', the current velocity, $U_{0}$, is constant along the vertical axis (collinear to the wave). The dispersion ratio is expressed as:

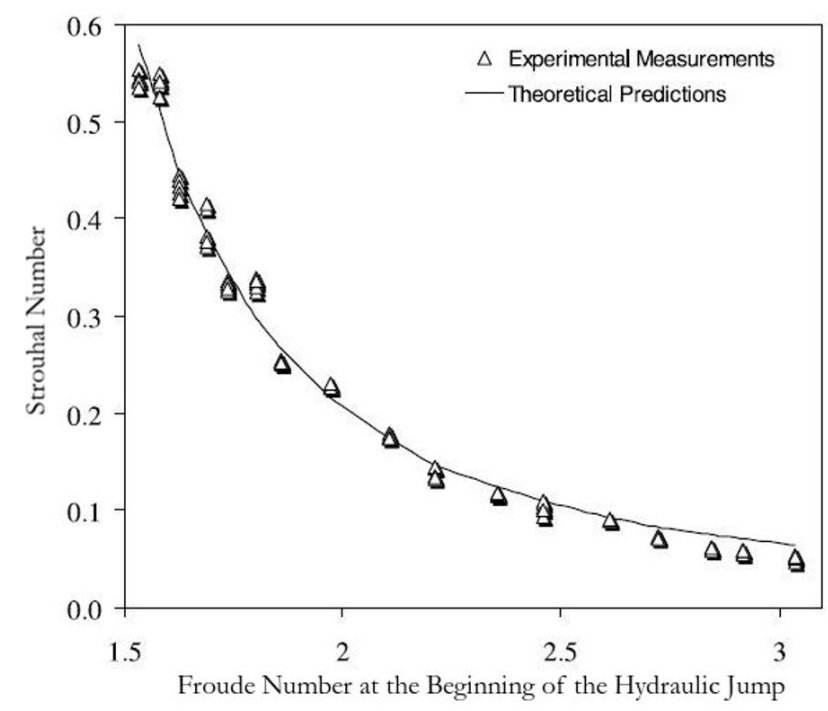

Figure 2. Characteristic frequencies of level oscillation downstream from a hydraulic jump. Source: Adapted from Mok (2004).

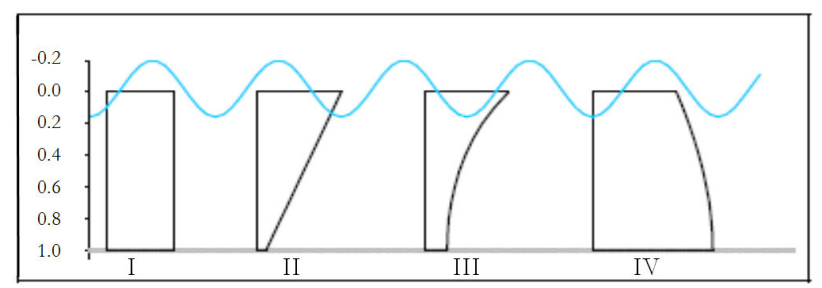

Figure 3. Types of vertical current profiles described as (from left to right): (I) uniform; (II) with constant vorticity; (III) exponential; and (IV) cosine. Source: Neves and Dias (2013). 
$\left(\omega-k U_{0}\right)^{2}=g k t a n h k h$

This expression is similar to the linear dispersion equation when the current is negligible. The only difference is that the intrinsic frequency $(\omega-\mathrm{kU})$ is substituting the apparent frequency $(\omega)$ when a fixed observer with respect to the bottom is considered.

For case 'II', with constant vorticity, the dispersion equation is expressed as:

$\left(\omega-k U_{s}\right)^{2}=\left\{g k-\Omega_{0}\left[\omega-k U_{s}\right]\right\} \tanh k h$

where $U_{s}$ is the velocity at the surface $(z=0)$, defined as:

$U_{s}=U_{0}+\Omega_{0} h$

and $U_{0}$ is the velocity at $z=-h$.

In case 'III', the dispersion equation is given by:

$\left(\omega-k U_{s}\right)^{2}=\frac{g k^{2} h \tanh \alpha h}{\alpha h-\gamma h \tanh \gamma h \tanh \alpha h}$

where $\alpha$ is calculated by Equation 16:

$\alpha=\sqrt{\gamma^{2}+k^{2}}$

For case 'IV', the form of the dispersion equation will depend on whether $k^{2}$ is smaller, equal to, or greater than $\gamma^{2}$.

$\left(\omega-k U_{s}\right)^{2}=\left\{\begin{array}{l}\frac{g k^{2} h \tan \beta h}{\beta h+\gamma h \tan \gamma h \tan \beta h}, s e k^{2}<\gamma^{2} \\ \frac{g k^{2} h}{1+\gamma h \tan \gamma h}, s e k^{2}=\gamma^{2} \\ \frac{g k^{2} h \tanh \beta h}{\beta h+\gamma h \tan \gamma h \tanh \beta h}, s e k^{2}>\gamma^{2}\end{array}\right.$

where $\beta$ is defined by Equation 18:

$\beta=\sqrt{\left|\gamma^{2}-k^{2}\right|}$

\section{MATERIAL AND METHODS}

The experiments were carried out in a partially reduced physical model of a stepped spillway with a downstream channel, installed at the Laboratory of Hydraulic Works from the Institute of Hydraulic Research (IHR) of the Federal University of Rio Grande do Sul (UFRGS). In a 1/10 scale, the model was $2.45 \mathrm{~m}$ high and $0.40 \mathrm{~m}$ wide, presenting a $5-\mathrm{m}$ long downstream channel. The stepped spillway had 33 steps total, $6 \mathrm{~cm}$ high and $4.5 \mathrm{~cm}$ wide each, presenting an inclination of approximately $53^{\circ}$ to the horizontal and a Creager-type weir. Downstream from the channel, there was a type of vertical lift floodgate and a piezometer for water depth verification. The model presented this configuration since its structure has been investigated as part of the research developed at IHR, in which this study is inserted. Figure 4, shown in the final section of this article, presents a scheme of the model used.

The model was fed by a lower reservoir through a system consisting of a centrifugal pump, which was controlled by a frequency inverter to adjust the simulated flow rates. The model flow control was performed by means of an electromagnetic meter incorporated in the power system. The downstream level in the channel was controlled by a floodgate and measured by a piezometer, both located at the end of the channel.

Two probes were installed along the channel (as shown in the scheme from Figure 4, to measure the variation of the free water surface elevation. These probes were of the capacitive type, consisting of two parallel stainless steel rods that were positioned perpendicular to the direction of wave propagation.

In order to identify the periods of the waves downstream from the hydraulic jump, a probe was installed at the end of the jump for each tested condition, in a region where there were no bubbles that could interfere with the measurements. The end of the hydraulic jump was identified by Equation 8 .

The characteristic wave periods were obtained at the end of the hydraulic jump by the measurements acquired by the probe, hereinafter referred to as the 1 st probe. A second probe was installed one meter downstream from the 1 st probe - hereinafter called the 2nd probe - to identify the behavior of the waves along a distance of one meter downstream from the hydraulic jump.

For the identification of the characteristic wave periods, measurements were performed simultaneously by the two probes for the flow rates of 40,60 and $80 \mathrm{l} \mathrm{s}^{-1}$, which were simulated in the stepped spillway reduced physical model. The minimum $\left(40 \mathrm{l} \mathrm{s}^{-1}\right)$ and maximum $\left(80 \mathrm{l} \mathrm{s}^{-1}\right)$ flow rates corresponded to the model limits due to the accuracy of the electromagnetic flow rate meter and due to the vibration of the equipment that measured water level variation (probes), respectively. In addition to those limits, an intermediate flow rate of $601 \mathrm{~s}^{-1}$ was also simulated in the physical model. All three flow rates represent the prototype specific flow rates at a $1 / 10$ scale with the model.

Table 3 presents the characteristics of the performed experiments, showing the flow rates tested in the model, the prototype specific flow rates, the Froude number at the beginning of the hydraulic jump, the water level in the channel downstream from the hydraulic jump (visually controlled), and the positions of the probes measuring free surface elevation. The tested conditions considered free and submerged hydraulic jumps with 10 and $20 \%$ submergence.

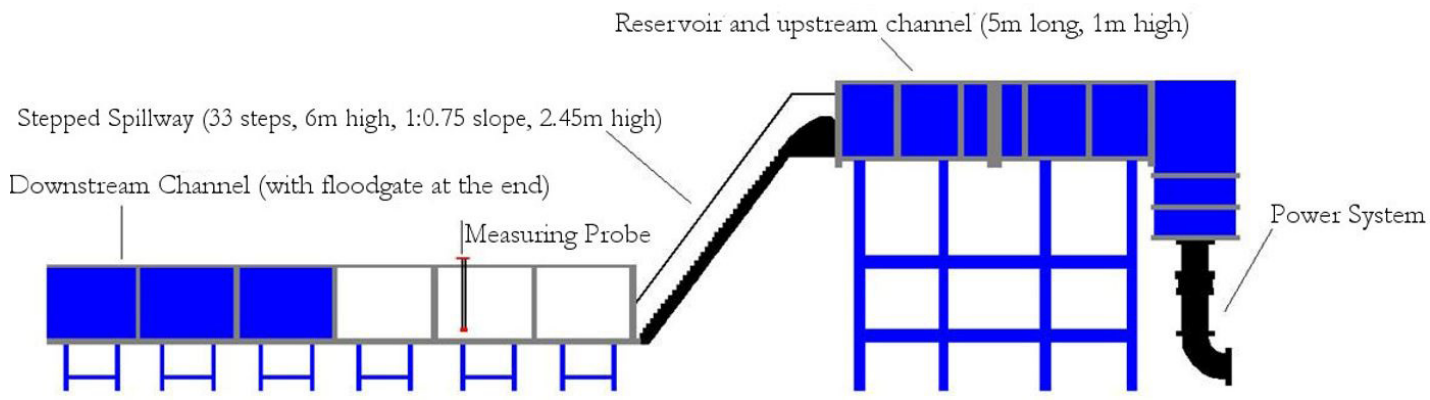

Figure 4. Schematic representation of the model used (flow direction from right to left). 
Table 3. Flow parameters and positions of the measuring level probes in the performed experiments for free and submerged hydraulic jumps.

\begin{tabular}{|c|c|c|c|c|c|c|}
\hline $\mathrm{Q}(1 / \mathrm{s})$ & $\mathrm{qp}\left(\mathrm{m}^{3} / \mathrm{s} / \mathrm{m}\right)$ & Fr1 & Probe & $S=1.0: \mathrm{d} 2=265 \mathrm{~mm}$ & $\mathrm{~S}=1.1: \mathrm{Tw}=289 \mathrm{~mm}$ & $\mathrm{~S}=1.2: \mathrm{Tw}=317 \mathrm{~mm}$ \\
\hline \multirow[t]{2}{*}{40} & 0.10 & 7.4 & $1 \mathrm{st}$ & 3.05 & 3.21 & 3.3 \\
\hline & & & 2nd & 4.05 & 4.21 & 4.3 \\
\hline$Q(1 / s)$ & $\mathrm{qp}\left(\mathrm{m}^{3} / \mathrm{s} / \mathrm{m}\right)$ & Fr1 & Probe & $\mathrm{S}=1.0: \mathrm{d} 2=339 \mathrm{~mm}$ & $\mathrm{~S}=1.1: \mathrm{Tw}=375 \mathrm{~mm}$ & $\mathrm{~S}=1.2: \mathrm{Tw}=408 \mathrm{~mm}$ \\
\hline \multirow[t]{2}{*}{60} & 0.15 & 7.0 & $1 \mathrm{st}$ & 4.17 & 4.12 & 4.29 \\
\hline & & & 2nd & 5.17 & 5.12 & 5.29 \\
\hline $\mathrm{Q}(1 / \mathrm{s})$ & $\mathrm{qp}\left(\mathrm{m}^{3} / \mathrm{s} / \mathrm{m}\right)$ & Fr1 & Probe & $\mathrm{S}=1.0: \mathrm{d} 2=409 \mathrm{~mm}$ & $\mathrm{~S}=1.1: \mathrm{Tw}=449 \mathrm{~mm}$ & $\mathrm{~S}=1.2: \mathrm{Tw}=490 \mathrm{~mm}$ \\
\hline \multirow[t]{2}{*}{80} & 0.20 & 6.9 & $1 \mathrm{st}$ & 4.76 & 4.78 & 4.74 \\
\hline & & & 2nd & 5.76 & 5.78 & 5.74 \\
\hline
\end{tabular}

For each flow condition presented in Table 3, three replicates of the experiments (called $\mathrm{T}_{1}, \mathrm{~T}_{2}$, and $\mathrm{T}_{3}$ ) were recorded, with a $200-\mathrm{Hz}$ acquisition frequency and a minimum duration of 5 minutes. From these records, the characteristic wave periods were obtained through temporal (time domain) and spectral (frequency domain) analysis.

Through the temporal analysis, the significant wave $\left(T_{s}\right)$ and mean $\left(\mathrm{T}_{\text {mean }}\right)$ periods were determined for each record. In order to do so, the "zero-up-crossing" method for wave definition was applied.

For the spectral analysis, the technique of spectral density function estimation proposed by Welch was used, besides a Hanning window with an approximate size of $1 / 16$ of the sample size. Through the spectral analysis, the peak period $\left(T_{p}\right)-$ i. e., the period corresponding to the maximum energy of the calculated spectrum - was determined for each of the obtained records.

From the identification of the characteristic periods of the waves downstream from the hydraulic jump, the relationship between the frequencies of vortices formed in the jump roller region and the frequency of waves downstream from the free hydraulic jump were verified using Equation 11 (Mok, 2004). The length of the roller contained within the hydraulic jump was obtained from Equation 6.

The frequencies identified through the inverse relationship among the periods were expressed in terms of the Strouhal number and related to the Froude number at the beginning of the hydraulic jump $\left(\mathrm{Fr}_{1}\right)$.

The Sontek YSI 16-MHz MicroADV (Acoustic Doppler Velocimeter) was used to measure the flow mean velocities in the flow conditions presented in Table 3. The measurements were taken in three different directions ( $\mathrm{x}, \mathrm{y}$, and $\mathrm{z}$ ) along several depth positions downstream from the hydraulic jump. The positions adopted for each flow condition were aimed to identify the velocity profile behavior at the same position relative to the hydraulic jump (similar to the location of the 1st probe, Figure 5).

The ADV measurements were performed at a $20-\mathrm{Hz}$ acquisition frequency. The samples were equal to or greater than 5 min long within the ADV working range of $\pm 100 \mathrm{~cm} \mathrm{~s}^{-1}$.

The wave length was obtained according to the presence of flow vorticity, derived from the ADV velocity profiles.

When the flow vorticity was zero, the wave length was determined by the dispersion equation (Equation 12). When the flow vorticity was constant, Equation 13 was used for that purpose.

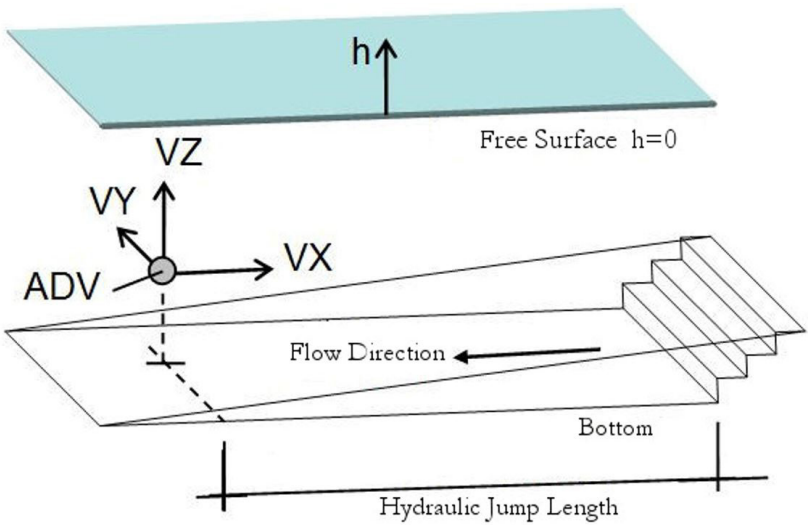

Figure 5. Position of the ADV and orientation of the positive velocity components measured by the ADV in the $\mathrm{x}-(\mathrm{Vx}), \mathrm{y}-(\mathrm{Vy})$ and $\mathrm{z}-(\mathrm{Vz})$ directions.

The wave propagation speed, i. e., the speed at which the wave travels along the channel, is called the 'wave celerity'. The wave celerity was determined by two distinct ways.

Firstly, the celerity was determined by obtaining the average time in which the wave propagated between two predefined consecutive measurement positions, which corresponded to the measurements performed between the 1 st and 2 nd probes. This average time was acquired by the highest correlation coefficient between time period and the values recorded between the probes. The wave celerity obtained through this procedure was denominated as 'observed celerity'.

The second procedure used to determine the wave celerity consisted of the $L / T$ ratio, i. e., the relationship between wave length $(L)$ and period $(T)$. The wave celerity associated with this method was denominated as 'theoretical celerity', which was obtained for the significant, peak, and mean periods.

\section{RESULTS}

Figure 6 shows the characteristic wave period data obtained at the end of the hydraulic jump for the free $(S=1.0)$ and submerged $(S=1.1$ and 1.2$)$ hydraulic jump conditions.

Figure 6 shows that the periods were clearly increasing as the flow rate increased, regarding both conditions of hydraulic jump formation. Another important aspect is that the characteristic wave periods were more related to the flow rate than to the condition of hydraulic jump formation. 
Figure 7 shows the relationship between the free surface variation frequencies (from 0.60 to $1.79 \mathrm{~Hz}$ ), measured in the experiments, and the estimated vortex formation frequencies in the roller region (from 1.04 to $1.32 \mathrm{~Hz}$ ). Furthermore, it is possible to identify that the free surface variation frequency derived from the significant wave periods - were more similar to observed values than the obtained vortex formation frequencies in the roller region.

Figure 8 shows the mean measured velocity components $\left(\mathrm{Vx}, \mathrm{Vy}\right.$, and $\mathrm{Vz}$ ) for the flow rates of 40,60 and $80 \mathrm{l} \mathrm{s}^{-1}$ and considering the condition of free hydraulic jump formed near the stepped spillway base.

At a flow rate of $40 \mathrm{l} \mathrm{s}^{-1}$, it is possible to observe a reasonable homogeneity in the $\mathrm{Vx}$ profile along $90 \%$ of the vertical axis (Figure 8a). The same did not occur at the other flow rates, 60 and $801 \mathrm{~s}^{-1}$, since the corresponding Vx profiles presented high slopes along the entire vertical axis. The Vy magnitudes (Figure 8b) indicate a tendency of the flow direction to be perpendicular to the predominant flow $(\mathrm{Vx})$, which means that significant intensities

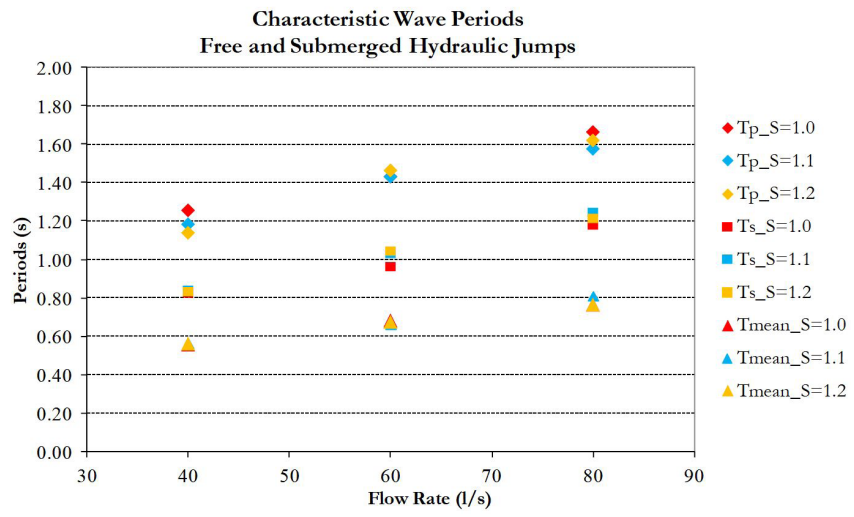

Figure 6. Characteristic wave periods for free and submerged hydraulic jump conditions (mean values derived from experiments). $T p, T s$, and Tmean are the peak, significant, and mean periods, respectively.

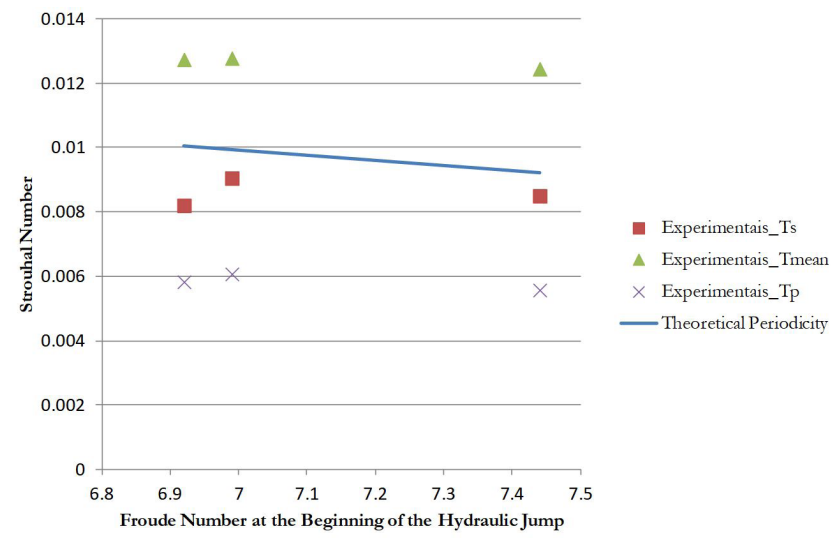

Figure 7. Comparison between the frequencies derived from the free surface variation downstream from the free hydraulic jump and the dimensionless theoretical frequency of vortex formation (Strouhal number). of this velocity component were verified towards the direction of one of the channel margins.

The Vz magnitudes were very close to zero (Figure 8c), which indicates that practically negligible values of the flow velocity were found perpendicular to the main flow direction, i. e., along the vertical axis.

The same flow pattern observed in the velocity profiles for the free hydraulic jump condition was verified for the submerged condition with 10 and 20\% submergence (Figure 9a-c and Figure 10a-c): homogeneous $\mathrm{Vx}$ vertical profile, flow tendency

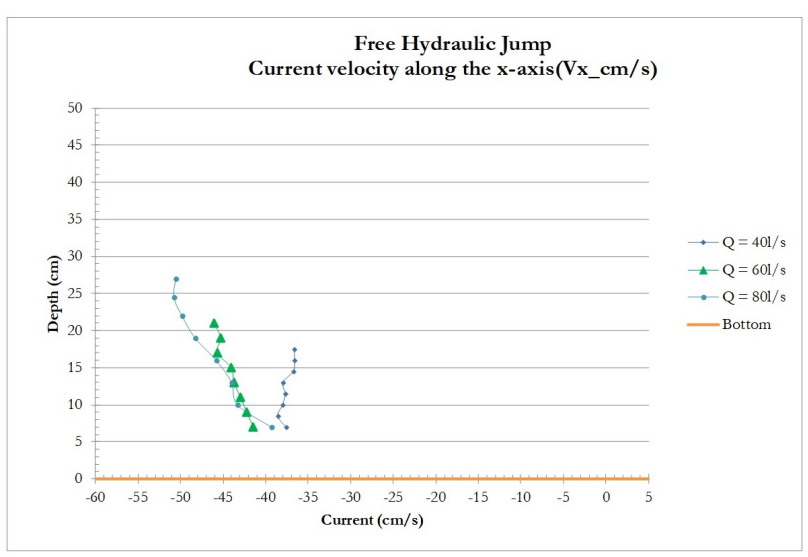

(a)

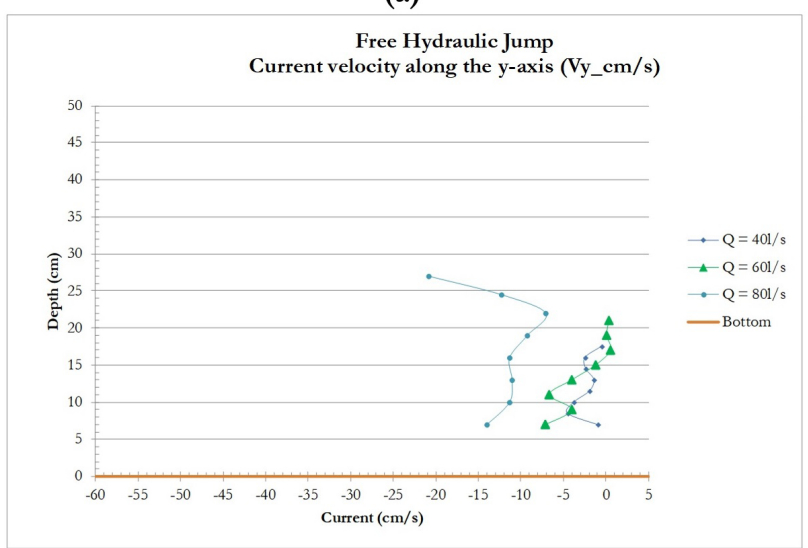

(b)

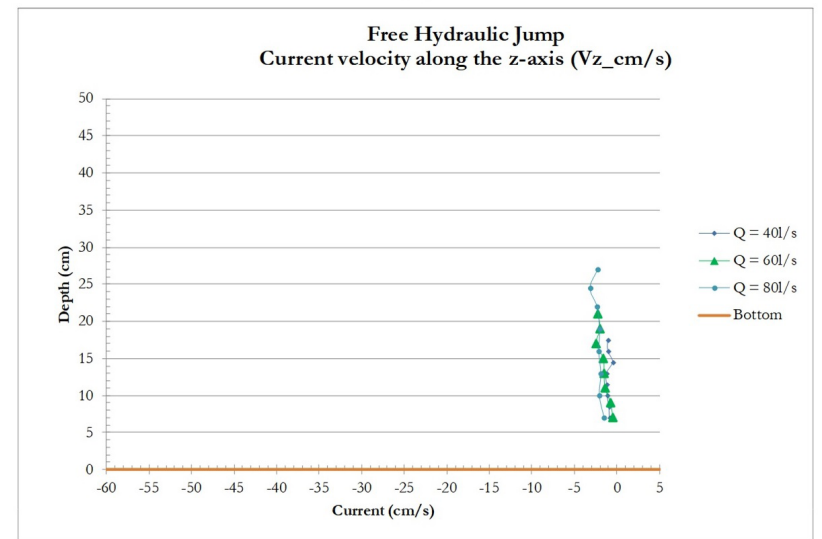

(c)

Figure 8. Mean measured velocity components, (a) Vx, (b) Vy, and (c) Vz, considering the free hydraulic jump condition. 
towards the direction of one of the channel margins $\left(V_{y}\right)$, and practically no flow with respect to the vertical axis $(\mathrm{Vz})$.

Figure 11 shows the obtained wave length $(L)$ for each wave characteristic of the 40,60 and $801 \mathrm{~s}-1$ flow rates, conditions of hydraulic jump formation, and characteristic wave period.

It is possible to observe in Figure 11 that the submergence condition did not have a significant influence on the wave length except for the wave lengths associated with the mean periods. Those wave lengths decreased as the submergence increased for all the conditions analyzed.

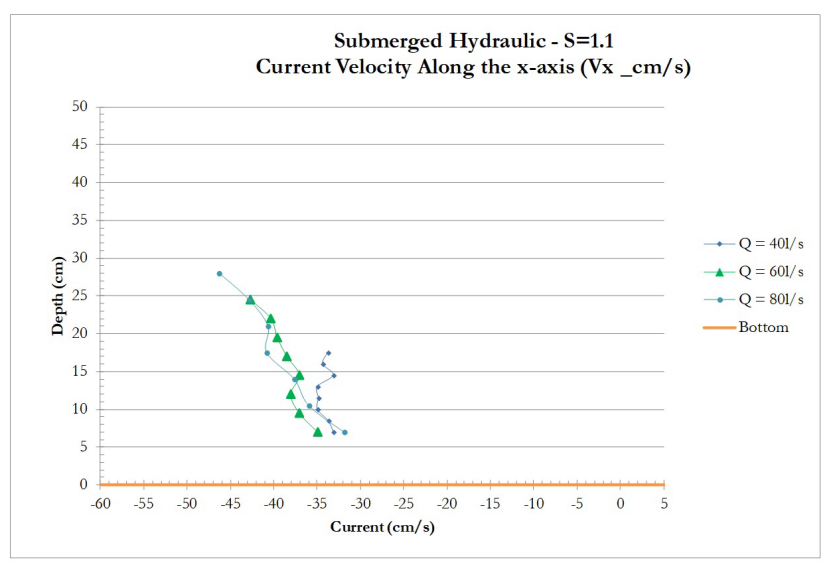

(a)

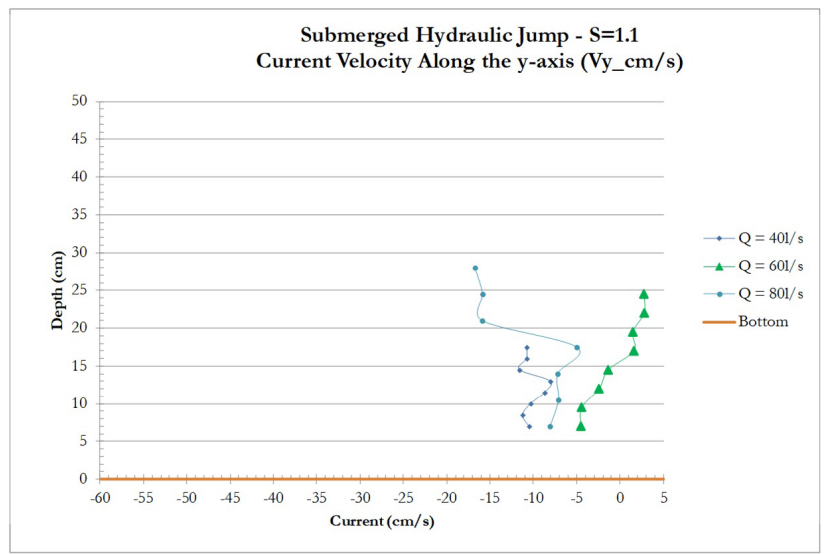

(b)

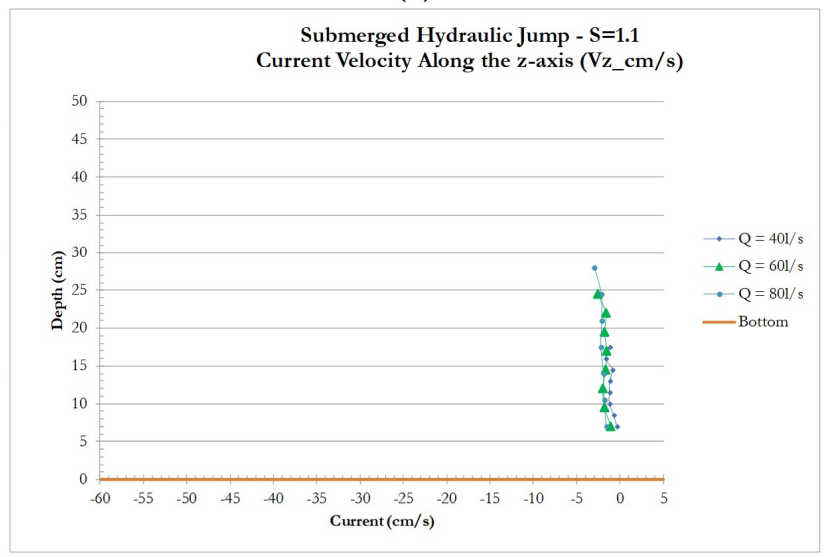

(c)

Figure 9. Mean measured velocity components, (a) Vx, (b) $V_{y}$, and (c) Vz, considering the submerged hydraulic jump condition with $10 \%$ submergence.
Figure 12 shows the results of observed and theoretical wave celerities for each characteristic wave period (presented in Figure 6).

Figure 12 shows that the observed wave celerity did not seem to be influenced by the depth increase downstream from the hydraulic jump, only influenced by the increase of the flow rate condition.

When comparing the celerities of the observed and theoretical waves (Figure 12), a maximum difference of $11 \%, 17 \%$, and $27 \%$ could be verified between the observed celerity and the theoretical celerities associated with the significant, peak, and mean periods, respectively.

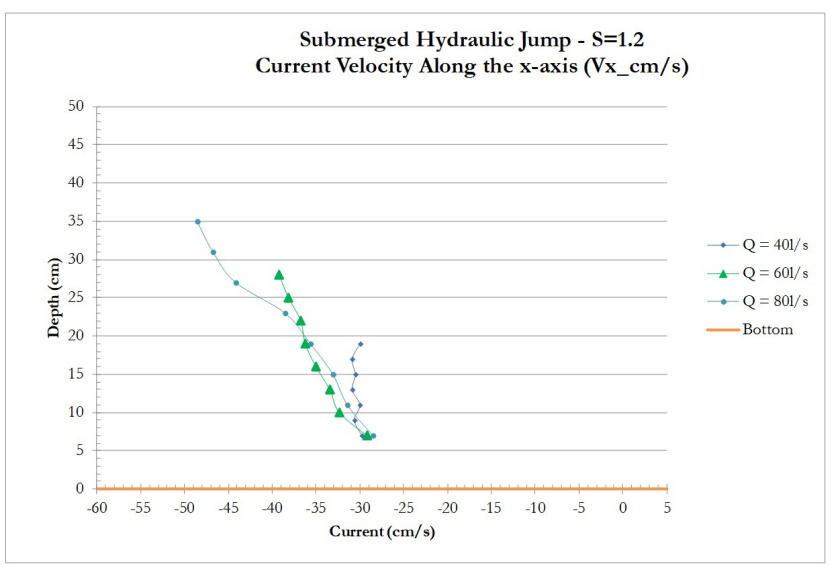

(a)

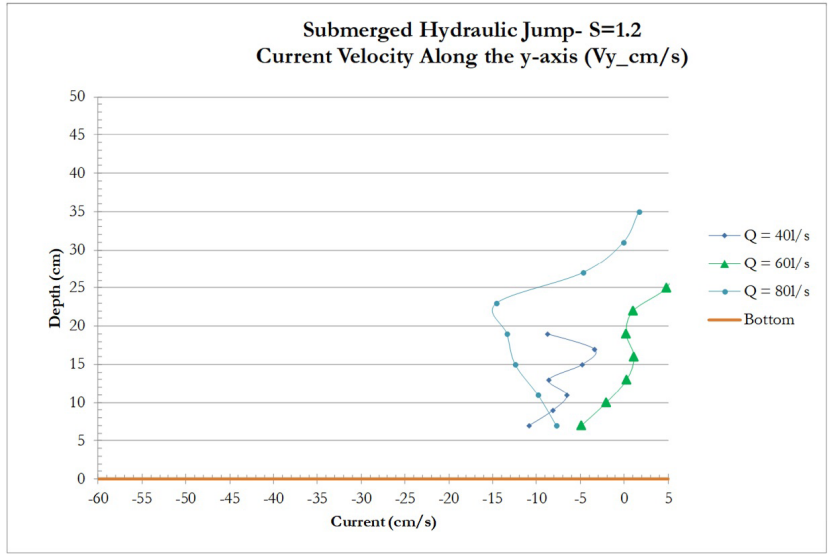

(b)

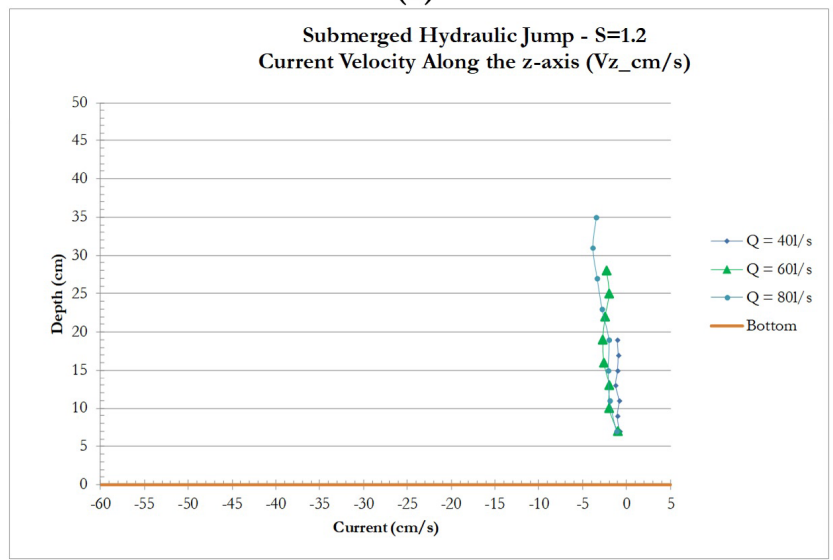

(c)

Figure 10. Mean measured velocity components, (a) Vx, (b) Vy, and (c) $\mathrm{Vz}$, considering the submerged hydraulic jump condition with $20 \%$ submergence. 


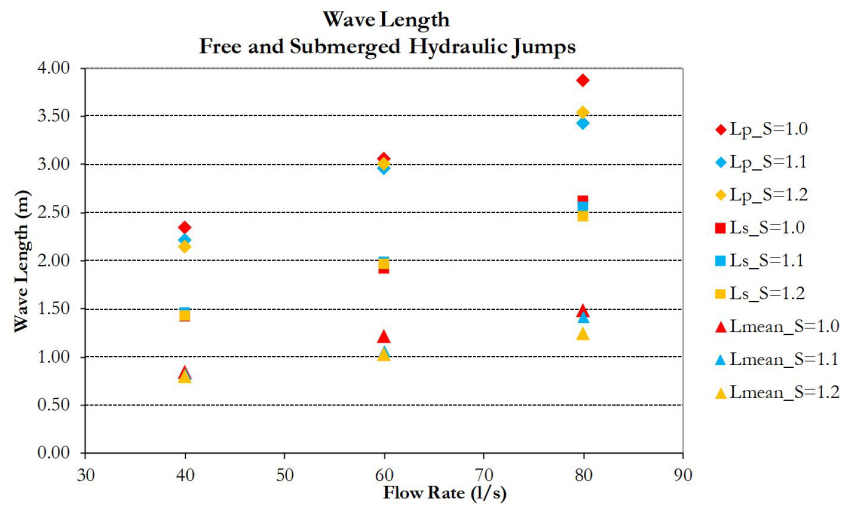

Figure 11. Wave length for each characteristic wave period and for the free and submerged hydraulic jump conditions; $L p, L s$, and Lmean are the wave lengths associated with the peak, significant, and mean periods, respectively.

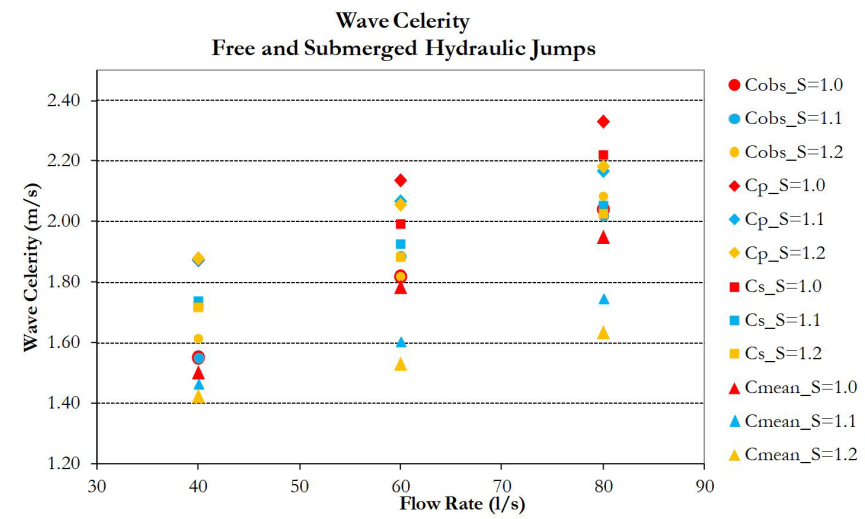

Figure 12. Wave celerity for each characteristic wave period and hydraulic jump condition (free and submerged). Cobs is the observed wave celerity and $C p, C s$, and Cmean are the theoretical wave celerities associated with the peak, significant, and mean periods, respectively.

Thus, it was possible to verify that the wave celerity estimated from the significant period yielded a better fit to the observed data than the wave celerity associated with the other periods.

\section{CONCLUSIONS}

The experiments carried out on a stepped spillway reduced physical model showed the possibility of identifying the characteristic parameters of waves generated downstream from an energy dissipater by free and submerged hydraulic jumps.

The analysis of the characteristic wave periods resulting from each simulated flow rate and submergence configuration showed a stronger correlation between the characteristic periods and the model flow rate than with the submergence condition of the formed hydraulic jump.

The frequency of waves generated downstream from the hydraulic jump - derived from the significant wave period - had a better correlation with the frequency of vortices from the roller region, thus demonstrating that this is the most representative period for the characterization of waves generated downstream from free and submerged hydraulic jumps.

Through the application of the dispersion equation, it was possible to consider the wave-current overlapping effect, which in turn allowed us to obtain the length and celerity of waves generated downstream from a hydraulic jump. The resulting relationship between theoretical (obtained from the dispersion equation) and observed data (acquired from measurements made in the reduced physical model) therefore confirmed again that the significant wave period is the most indicated for the characterization of waves generated downstream from free and submerged hydraulic jumps.

\section{ACKNOWLEDGEMENTS}

The authors thank Dona Francisca Energética S/A for funding the research project, the team from the Laboratory of Hydraulic Works from the IHR/UFRGS for the assistance provided during the course of the research process, and CNPQ for the financial support.

\section{REFERENCES}

ABOU-SEIDA, M. M. Wave action below spillways. Journal of the Hydraulics Division, v. 89, n. HY3, p. 133-152, 1963.

BRADLEY, J. N.; PETERKA, A. J. Hydraulic design of stilling basins: stilling basin and wave suppressors for canal structures, outlet works, and diversion dams (Basin IV). Journal of the Hydraulic Division, v. 83, n. 5, p. 1-20, 1957.

CONTERATO, E. Determinação de critérios de dimensionamento de soleira terminal em bacia de dissipação a jusante de vertedouro em degraus. 2014. 156 f. Dissertação (Mestrado em Recursos Hídricos e Saneamento Ambiental) - Universidade Federal do Rio Grande do Sul, Porto Alegre, 2014.

ELEVATORSKI, A. E. Hydraulic energy dissipators. New York: McGraw-Hill, 1959.

LOPARDO, R. A.; FATTOR, C. A.; CASADO, J. M.; LOPARDO, M. C. Uma aproximación turbulencia remanente de la longitud del Resalto Sumergido. In: CONGRESSO LATINO AMERICANO DE HIDRÁUliCA, 21., 2004, São Pedro. Anais... São Pedro: International Association of Hydro-Environment Engineering and Research, 2004. 9 p.

LOPARDO, R. A.; VERNET, G. F. Ondas aguas abajo de disipadores a resalto. In: CONGRESSO LATINOAMERICANO DE HIDRAULICA, 8., 1978, Quito. Anales... Equador, 1978.

MARQUES, M. G.; ALMEIDA, F. M.; ENDRES, L. A. M. Adimensionalização de pressões médias em bacias de dissipação por ressalto hidráulico. In: SIMPÓSIO BRASILEIRO DE RECURSOS HÍDRICOS, 13., 1999, Belo Horizonte. Anais... Belo Horizonte: ABRH, 1999. 
MARQUES, M. G.; DRAPEAU, J.; VERRETTTE, J. L. Flutuação de pressão em um ressalto hidráulico. In: CONGRESSO LATINOAMERICANO DE HIDRÁULICA, 17., 1997, Guayaquil. Anais... Equador, 1997.

MOK, K. M. Relation of surface roller eddy formation and surface fluctuation in hydraulic jumps. Journal of Hydraulic Research, v. 42, n. 2, p. 207-212, 2004. http://dx.doi.org/10.1080/00221686.2004.9728383.

NEVES, C.; DIAS, A. A importância da caracterização da corrente para a correta determinação do comprimento e da altura das ondas. Parte 1: embasamento teórico e dispersão. Revista Brasileira de Recursos Hídricos, v. 18, n. 3, p. 215-229, 2013. http://dx.doi. org/10.21168/rbrh.v18n3.p215-229.

PETERKA, A. J. Hydraulic desing of stilling basins and energy dissipators. Denver: U.S. Department Interior, Bureau of Reclamation, 1974. (Engeneering Monograph, 25).

RAJARATNAM, N. Submerged hydraulic jump. Journal of the Hydraulics Division, v. 91, n. 4, p. 71-96, 1965.

TEIXEIRA, E. D. Previsão dos valores de pressão junto ao fundo em bacias de dissipação por ressalto hidráulico. 2003. 113 f. Dissertação
(Mestrado em Engenharia) - Programa de Pós-graduação em Recursos Hídricos e Saneamento Ambiental, Instituto de Pesquisas Hidráulicas, Universidade Federal do Rio Grande do Sul, Porto Alegre, 2003.

TRIERWEILER NETO, E.F. Avaliação do campo de pressões em ressalto bidráulico formado a jusante de uma comporta com diferentes graus de submergência. 2006. 174 f. Dissertação (Mestrado em Engenharia) - Universidade Federal do Rio Grande do Sul, Porto Alegre, 2006.

\section{Authors contributions}

Ana Paula Gomes: Lead author of the paper, she participated in all phases of the study.

Eduardo Pivatto Marzec: participated in the study and his specific contribution was: design and research design, data acquisition, data analysis and Interpretation.

Luiz Augusto Magalhães Endres: Writing of the manuscript and critical revision of the manuscript regarding the intellectual content. 